\title{
A Visão Atual da Indicação Cirúrgica das Cardiopatias Congênitas
}

\author{
Edmar Atik
}

São Paulo, SP

A indicação para a correção cirúrgica da maioria das cardiopatias congênitas tornou-se hoje rotineira e quase que sistemática, logo após a caracterização diagnóstica, em face dos indiscutíveis avanços nos vários campos de atuação da cardiologia pediátrica, em especial no cirúrgico ${ }^{1-3}$.

Dessa maneira, uma das perguntas que intrigam no manejo atual da especialidade, e que deve ser abordada mais apropriadamente, corresponde à que se todos os pacientes com cardiopatias congênitas devam ser reparados, cirurgicamente.

Para essa resposta, importa recordarmos, inicialmente, os já bem estabelecidos parâmetros de indicação cirúrgica, em presença de uma cardiopatia congênita ${ }^{3}$. Aliás, dessa análise cuidadosa resulta a justificável indicação operatória ou a rara orientação expectante atual.

Assim, a longevidade segundo a história natural, o risco cirúrgico e o tipo de evolução pós-operatória são devidamente analisados para cada caso, a fim de se adotar a conduta mais adequada.

Como o risco cirúrgico tem-se tornado até desprezível em muitas cardiopatias, especialmente dentre as acianogênicas, é fácil entender a preponderância da conduta intervencionista atual ${ }^{1,2}$.

Posição contrária à operação é estabelecida apenas em situações nas quais a longevidade natural sobrepuje à apresentada pela evolução pós-operatória, quando esta é obscurecida pela morbidade ocasionada por lesões residuais, por complicações e por seqüelas operatórias. Dado o progresso técnico atual, esta atitude conservadora tem-se tornado cada vez mais rara.

Cresce daí a indicação, mesmo em períodos precoces da vida, de operações eletivas a fim de prevenir complicações evolutivas, que habitualmente ocorrem na história natural dessas cardiopatias. Por isso, aceita-se hoje a indicação mesmo em cardiopatias de discreta repercussão. Assim, consegue-se a adequada prevenção de intercorrências, que certamente interferem e aumentam a morbidade pós-operatória como, por exemplo, o aparecimento de lesão valvar aórtica em estenoses subaórticas, de distorção da aorta e de

Instituto do Coração do Hospital das Clínicas - FMUSP

Correspondência: Edmar Atik - Incor - Av. Enéas C. Aguiar, 44 - 05403-000 - São Paulo, SP

Recebido para publicação em 20/3/98

Aceito em 23/4/98 hipertensão arterial (HA) em coartação da aorta, de endocardite infecciosa em comunicação interventricular(CIV)e no canal arterial pérvio e de disrritmias cardíacas na comunicação interatrial (CIA).

Essa conduta é reforçada por evidências que salientam a maior ocorrência da temida endocardite infecciosa nestas cardiopatias, exceção à CIA, em proporção de até duas vezes superior ao risco cirúrgico atual ${ }^{1,2}$.

Acentuando ainda mais a quase que liberal indicação operatória atual, são inúmeros os exemplos de pacientes com coartação da aorta com HA na idade adulta, que quando crianças, presença de gradientes discretos de pressão constituíam-se na razão da objeção à cirurgia precoce.

Por outro lado, a contra-indicação cirúrgica é guiada por evidências de que a longevidade natural sobrepuje à apresentada pela evolução pós-operatória ou ainda em situações nas quais os defeitos são discretos a ponto de não interferirem na evolução natural e, ainda, não sofrerem alterações significativas após eventuais correções. Tais situações ocorrem em lesões obstrutivas do coração direito ou esquerdo como nas estenoses valvares, pulmonar e aórtica, quando estas se apresentem em grau discreto. E ainda mais na hipertensão pulmonar na qual a morbidade operatória também suplanta a apresentada pela evolução natural desta enfermidade.

Nesse mesmo contexto, entende-se a contra-indicação operatória, especialmente em relação a técnicas corretivas, em presença de síndromes genéticas, quando a longevidade natural da própria síndrome for menor que a da cardiopatia concomitante, esta geralmente de discreta a moderada repercussão. Aplica-se essa condição a portadores da síndrome de Down com defeitos de discreta repercussão anátomo-funcional, como eventualmente pode ocorrer com a CIA associada, com a CIV e por vezes até no defeito total do septo atrioventricular. É óbvio que a conduta seja similar em qualquer outra síndrome genética, desde que o defeito não se mostre com acentuada repercussão hemodinâmica. No entanto, em presença de grandes defeitos, não se deve descartar a possibilidade da execução de operações paliativas, tipo bandagem pulmonar a fim de melhorar a qualidade da vida de crianças atingidas por alterações genéticas acentuadas, como se sucede por exemplo na síndrome de Edwards (trissomia 13), ou na de Patau (trissomia 18), nas quais sabidamente a longevidade não ultrapassa o $1^{\circ}$ ano de vida. Mesmo assim, em face de grande comunicação interventricular associada, a qualidade de vida desses pacientes pode melhorar com a realização de cirurgias paliativas. 
Essas considerações não se aplicam à síndrome de Down (trissomia 21) cuja perspectiva de vida é maiore assim a correção operatória de grandes defeitos é sempre considerada, caso não haja hipertensão pulmonar.

Da análise da história natural dos defeitos cardíacos conjuntamente com a apresentada pelas síndromes genéticas, surge orientação para a conduta conservadora, corretiva ou mesmo paliativa.

Há que se considerar também situações nas quais, pelo maior risco cirúrgico aliado a discreto benefício pós-operatório obtido, diminui o entusiasmo pela intervenção cirúrgica, caracterizando o que se pode chamar de contra-indicação relativa à operação, na qual, no entanto, as opiniões podem divergir sobremaneira. Correspondem a situações nas quais se colocam o risco em um dos pratos da balança e no outro o real benefício. Como exemplos concretos, cito inicialmente a síndrome de Cimitarra com drenagem anômala infradiafragmática do pulmão direito hipoplásico com discreto hiperfluxo pulmonar, cuja relação do fluxo pulmonaré menor que 1,5:1 em relação ao fluxo sistêmico. A seguir, menciono a atresia pulmonar associada à CIV com poucos e hipoplásicos segmentos arteriais conexionados às artérias pulmonares, as estenoses pulmonares múltiplas, as cardiopatias complexas com isomerismo atrial direito associadas à atresia pulmonare à drenagem anômala total de veias pulmonares infradiafragmática e ainda a cardiopatias acianogênicas, como a CIA, que se acompanham de hipoplasia mitral.

Estende-se essa situação a cardiopatias neonatais que não se beneficiam com o tratamento clínico, como na anomalia de Ebstein, na agenesia da valva pulmonar e na hipoplasia do coração esquerdo, cujas correções mesmo paliativas são de alto risco ${ }^{1,3}$.

Entendo que apesar do risco operatório nessas condições exceder até a $80 \%$, mesmo em instituições especializadas como no Incor-FMUSP, a relativa contra-indica- ção deve ceder lugar à procura de táticas clínicas e técnicas cirúrgicas que visem diminuir esse até proibitivo risco atual.

Essa procura orienta à melhor terapêutica e a cuidados per e pós-operatórios a fim de adequar cada vez mais os fluxos pulmonar e sistêmico.

Pelo exposto, devem ser combatidas, na maioria das vezes, posições contrárias à indicação cirúrgica, que hoje vivenciamos na cardiologia pediátrica. O clínico deve se posicionar contrário à época inoportuna da indicação, a qual deve ser precoce, tão precoce que não surjam possibilidades mesmo discretas para o aparecimento de quaisquer fatores adquiridos que venham a obscurecer os resultados a longo prazo.

Aliás, foi através dessa norma de conduta mais precoce que se obteve a cura de anomalias, anteriormente temidas, como a transposição das grandes artérias, a drenagem anômala total das veias pulmonares e, mais recentemente, a correção da tetralogia de Fallot, já no período neonatal ${ }^{3}$.

Estas efetivas correções precoces provam a necessidade da eliminação dos fatores adversos anatômicos e funcionais, adquiridos com o tempo. Em base desses aspectos, tem se orientado para a correção programada da hipoplasia do coração esquerdo, já nas primeiras horas de vida, antes do aparecimento dos sinais de baixo débito cardíaco ou de insuficiência cardíaca, em face do valioso diagnóstico ecocardiográfico estabelecido em período pré-natal.

Antes do advento da outra era da cardiologia pediátrica, qual seja a do conhecimento dos aspectos etiopatogênicos, indispensável para a prevenção adequada das cardiopatias congênitas, resta-nos no momento melhorar a condição de vida destes cardiopatas.

Para tal, tornou-se meta importante a obtenção de uma população normal, mesmo dentre os portadores de cardiopatias congênitas, através do reconhecimento e correção operatória precoces.

\section{Referências}

1. Kirklin JW, Barratt-Boyes BG - Cardiac Surgery - $2^{\text {nd }}$ ed. New York: Churchill Livingstone, 1993.

2. Santana MVT, Silva MAP, Silva Jr JP - Indicação cirúrgica das cardiopatias congênitas acianogênicas. In: Sousa AGMR, Mansur AJ - Socesp Cardiologia. $2^{\circ}$ volume. São Paulo: Atheneu, 1996: 837-44.

3. Atik E, Atik FA - Momento da indicação cirúrgica das cardiopatias congênitas cianogênicas. In: Sousa AGMR, Mansur AJ - Socesp Cardiologia. $2^{\circ}$ vol. São Paulo: Atheneu, 1996: 813-28. 